\title{
Role of neutrophil elastase in ozone-induced airway responses in guinea-pigs
}

\author{
K. Matsumoto, H. Aizawa, H. Inoue, H. Koto, H. Nakano, N. Hara
}

Role of neutrophil elastase in ozone-induced airway responses in guinea-pigs. $K$. Matsumoto, H. Aizawa, H. Inoue, H. Koto, H. Nakano, N. Hara. (C) ERS Journals Ltd 1999. ABSTRACT: Ozone-induced airway hyperresponsiveness occurs concurrently with neutrophilic inflammation and epithelial injury in various species including humans. The mechanism of neutrophil-induced airway hyperresponsiveness, however, has not yet been fully clarified. Neutrophil elastase (NE) is a multipotent protease released from activated neutrophils, which may play a role in ozone-induced airway hyperresponsiveness. In order to address this issue, the effects of ONO-5046, a specific NE inhibitor, were investigated in ozone-exposed guinea-pigs.

Awake animals were exposed to ozone at 3 parts per million for $2 \mathrm{~h}$, airway responsiveness to acetylcholine (ACh) measured and examination of bronchoalveolar lavage fluid (BALF) performed.

Ozone exposure increased airway responsiveness to both inhaled and intravenous $A C h$, the concentration of $N E$ in BALF and the number of neutrophils and airway epithelial cells in BALF. Although pretreatment with ONO-5046 $\left(200 \mathrm{mg} \cdot \mathrm{kg}^{-1}\right.$, i.p. $)$ had no effect on these changes immediately after the exposure, it significantly inhibited airway hyperresponsiveness to inhaled $\mathrm{ACh}$, whilst decreasing the number of neutrophils and epithelial cells in BALF 3-5 h after the exposure. In contrast, ONO5046 showed no significant effect on airway hyperresponsiveness to intravenous ACh at any time.

These results suggest that neutrophil elastase contributes to ozone-induced airway hyperresponsiveness developing during the hours after exposure, presumably by means of inducing epithelial injury.

Eur Respir J 1999; 14: 1088-1094.

Research Institute for Diseases of the Chest, Faculty of Medicine, Kyushu University, 3-1-1 Maidashi, Higashi-ku, Fukuoka 812-8582, Japan.

Correspondence: H. Aizawa

Research Institute for Diseases of the Chest Faculty of Medicine

Kyushu University

3-1-1 Maidashi

Higashi-ku

Fukuoka 812-8582

Japan

Fax: 81926425389

Keywords: Acetylcholine

airway hyperrresponsiveness

elastase

guinea-pig

neutrophil

Received: November 251998

Accepted after revision May 271999

Airway hyperresponsiveness and inflammation are characteristic features of asthma. Although eosinophilic airway inflammation is generally observed in patients with asthma [1], infiltration of neutrophils is also detected in the airways of patients with acute severe asthma [2, 3]. However, the pathophysiological role of neutrophils in airway hyperresponsiveness has not yet been fully clarified [4]. Ozone exposure causes airway hyperresponsiveness associated with neutrophilic airway inflammation in various species including humans [5-12]. Such evidence strongly raises the possibility that neutrophilic inflammation may contribute to the development of ozone-induced airway hyperresponsiveness, although the precise mechanism of this is still unknown. This possibility remains controversial since several studies have reported the lack of evidence for a contribution of neutrophils to ozoneinduced airway hyperresponsiveness $[13,14]$.

A previous study reported that both the concentration and activity of neutrophil elastase (NE) significantly increased in the bronchoalveolar lavage fluid (BALF) of ozone-exposed normal subjects [10]. Recent studies have shown NE concentration to increase in the sputum and bronchial lavage fluid of asthmatics, in particular, in patients with noninfectious status asthmaticus $[3,15]$. In addition, aerosolized human $\mathrm{NE}$ has been reported to induce airway hyperresponsiveness in guinea-pigs, and histological examination of intrapulmonary bronchi revealed marked epithelial injury [16]. These studies suggest that NE may play a pivotal role in airway hyperresponsiveness in both ozone-exposed subjects and asthmatics.

The integrity of the airway epithelial layer may be a key determinant of airway responsiveness. The loss of epithelial barrier function induces airway hyperresponsiveness by facilitating the diffusion of inhaled bronchoconstrictors to the airway smooth muscle [17]. Furthermore, the epithelium has been known to release inhibitory modulators of airway responsiveness, such as prostaglandin $\mathrm{E}_{2}\left(\mathrm{PGE}_{2}\right)$, nitric oxide, and epithelium-derived relaxing factors (EpDRFs) [18-22]. Owing to the fact that general desquamation of epithelium is another feature of ozoneexposed airways, it is conceivable that NE may contribute to the development of ozone-induced airway hyperresponsiveness, possibly by inducing epithelial injury [23, 24].

In the present study, the effects of ONO-5046, a currently available inhibitor of human NE, on the airway inflammation and hyperresponsiveness induced by ozone exposure in guinea-pigs were examined [25]. In order to determine whether NE is responsible for the epithelial injury, the effects of ONO-5046 on airway hyperresponsiveness between animals administered with inhaled and 
intravenous-acetylcholine (ACh) were compared. This approach was based on previous work showing that the disturbance of epithelial integrity is reflected in the difference in airway responsiveness to inhaled and to intravenous bronchoconstrictors [26, 27].

\section{Methods}

\section{Experimental protocol}

Male Hartley guinea-pigs (500-550 g) were used in this study. Airway responsiveness to inhaled and to intravenous ACh was measured, and examinations of BALF performed, in separate animals in order to eliminate the possible interference between the procedures. Each measurement was performed using five animals. The measurements were made before, immediately after, and 3 and $5 \mathrm{~h}$ after ozone exposure. ONO-5046 was used as an NE inhibitor, because it has been reported to inhibit guinea-pig NE activity in a concentration-dependent manner (inhibitory concentration of $50 \%$ IC50) $23.2 \pm 1.2 \mathrm{nM}$ ), and the reported inhibition was competitive, with an inhibitory constant $(K \mathrm{i})$ of $7.65 \pm$ $0.62 \mathrm{nM}$ by means of Dixon analysis [28]. Vehicle $(0.9 \%$ saline) or ONO-5046 (200 mg. $\left.\mathrm{kg}^{-1}\right)$ was intraperitoneally administered to the animals $30 \mathrm{~min}$ prior to ozone expusure.

Ozone exposure was performed as previously described [12]. The animals inhaled dry air or $3.0 \pm 0.1$ parts per million (ppm) (mean $\pm \mathrm{SD})$ ozone for $2 \mathrm{~h}$ while awake and breathing spontaneously in a $24 \mathrm{~L}$ exposure chamber. Ozone was generated by passing $100 \%$ oxygen through an ozonator (Model 0-1-2; Nihon Ozone, Tokyo, Japan), which was regulated by means of a variable voltage supply. The concentration of ozone in the chamber was continuously monitored using an ultraviolet analyser (Model 1500; Dasibi, Glendale, CA, USA).

\section{Measurement of airway responsiveness}

The guinea-pigs were anaesthetized with $50 \mathrm{mg} \cdot \mathrm{kg}^{-1}$ pentobarbital sodium administered intraperitoneally. The animals were intubated via a tracheotomy and were then mechanically ventilated using a respirator (Model No. 680; Harvard Apparatus; South Natick, MA, USA) at a constant tidal volume of $7 \mathrm{~mL} \cdot \mathrm{kg}^{-1}$ and a frequency of 60 breaths $\cdot \mathrm{min}^{-1}$. A catheter was introduced into a jugular vein to administer the drugs. Another catheter was inserted into a carotid artery, through which the blood pressure was measured via an electric manometer (LPU-0.1; Nihon Kohden, Tokyo, Japan). In order to estimate pleural pressure, a fluid-filled catheter was introduced into the oesophagus at a point at which the maximal amplitude of pressure was obtained. The animals were placed supine in a flow-type body plethysmograph made of plexiglas and with 2.8 L of dead space (customized; Chest Medical, Tokyo, Japan). The plethysmograph airflow was measured using a Fleisch pneumotachograph (TV-132T; Nihon Kohden) and a differential pressure transducer (TP-602T; Nihon Kohden). The transpulmonary pressure was estimated from the difference between the oesophageal and airway opening pressure, measured by means of a differential pressure transducer (TP-603T; Nihon Kohden). The total pulmonary resistance $(R \mathrm{~L})$ was calculated from transpulmonary pressure and plethysmograph airflow.
Airway responsiveness to inhaled ACh was determined by inhalation of an increasing concentration of ACh administered via the endotracheal tube. The ACh aerosol (output $1.5 \mathrm{~mL} \cdot \mathrm{min}^{-1}$ ) was generated by means of an ultrasonic nebulizer, (TUR-3200; Nihon Kohden) placed in line with the ventilator. The dose/response curves were constructed as follows: saline aerosol was given for 15 breaths, and the subsequent $R \mathrm{~L}$ value was used as baseline. The ACh aerosol was administered for 15 breaths, separated by 5 -min intervals. The concentration of ACh was increased for each series of 15 breaths. $R \mathrm{~L}$ was monitored for 5 min after each nebulization, and the maximum value was plotted against the ACh concentration. To achieve a constant-volume history, hyperinflation (three tidal volumes) was induced between each ACh challenge. The challenge was stopped when $R \mathrm{~L}$ exceeded $200 \%$ of baseline. The provocative concentration of $\mathrm{ACh}$ required to produce a $200 \%$ increase in $R \mathrm{~L}(\mathrm{PC} 200)$ was calculated by log-linear interpolation in individual animals.

Airway responsiveness to intravenous ACh was measured using a protocol similar to that used for inhaled ACh. Briefly, the dose/response curves were constructed as follows: $1 \mathrm{~mL} \cdot \mathrm{kg}^{-1}$ saline was given for $5 \mathrm{~s}$, and the subsequent $R \mathrm{~L}$ value used as baseline. The ACh solution, 1 $\mathrm{mL} \cdot \mathrm{kg}^{-1}$, was administered for $5 \mathrm{~s}$, separated by $5-\mathrm{min}$ intervals. The concentration of ACh was increased for each series of administration. $R \mathrm{~L}$ was monitored for $5 \mathrm{~min}$ after each administration, and the maximum value was plotted against the ACh concentration. The PC200 was calculated by log-linear interpolation in individual animals.

\section{Bronchoalveolar lavage}

Guinea-pigs were sacrified and bronchoalveolar lavage performed as previously described [12]. Both lungs were gently lavaged three times with $10 \mathrm{~mL} 0.9 \%$ saline via the tracheal cannula at a pressure of $25 \mathrm{cmH}_{2} \mathrm{O}$. The total cell counts including desquamated epithelial cells were determined using light microscopy and a standard haemocytometer. The lavage fluid was immediately centrifuged for $10 \mathrm{~min}$ at $200 \times g$ at $4^{\circ} \mathrm{C}$. The cell pellet was resuspended in saline, and Cytospin preparations (Cytospin 3; Shandon, Pittsburgh, PA, USA) were carried out. Differential counts on 500 cells were performed using light microscopy and a single-blind method following a modified Wright-Giemsa stain (Diff-Quick; Baxter, McGaw Park, IL, USA). The viability of the recovered cells was evaluated using the trypan blue exclusion test. In the supernatant of the BALF from the animals treated with vehicle, the concentration of NE- $\alpha-1$-protease inhibitor $\left(\alpha_{1}-\mathrm{PI}\right)$ complex (NE-PI) was measured by means of an enzyme immunoassay as described below.

\section{Measurement of neutrophil elastase in bronchoalveolar lavage fluid}

NE was measured by means of an enzyme immunoassay as a complex with $\alpha_{1}$-Pi (Merck, Darmstadt, Germany). The samples were added to wells coated with sheep antiNE elastase immunoglobulin G (IgG). This antibody does not cross-react with cathepsin $G$ or other neutrophil proteinases. After incubation and washing, the solid phasebound NE-PI was further incubated with alkaline phosphatase-labelled rabbit, anti-NE-PI IgG. After further 
washing, $p$-nitrophenylphosphate was added to measure the amount of solid phase-bound NE-PI. This assay was calibrated using a standard solution of known NE-PI concentration. The lower detection limit of this assay was $25 \mu \mathrm{g} \cdot \mathrm{L}^{-1}$. All data were expressed as the mean values of duplicate determinations.

\section{Measurement of ONO-5046 concentration in plasma}

Venous blood ( $1 \mathrm{~mL}$ ) was collected, using a heparinized syringe, from animals pretreated with ONO-5046. The blood samples were centrifuged for $30 \mathrm{~min}$ at $1500 \times g$ at $4^{\circ} \mathrm{C}$, and then their supernatants collected as plasma. The plasma concentration of ONO-5046 was measured by means of high-performance liquid chromatography (HPLC). Briefly, the sample $(0.5 \mathrm{~mL})$ was diluted with distilled water and $1 \mathrm{~N} \mathrm{HCl}$, and then applied to a Sep-Pak $\mathrm{C}_{18}$ short column (Waters, Milford, MA, USA). The sample and standard solutions of ONO-5046 were eluted with methanol from the short column, and the methanol solution was applied to a Bond Elut SAX short column (Varian, Horbor City, CA). The sample and standard solutions from the short column and the compounds in this solution were extracted using ethylacetate. The organic phase was evaporated to dryness and the residue was dissolved in $150 \mu \mathrm{L}$ of mobile phase and subjected to HPLC (LC-module-1; Waters, Milford, MA, USA). An aliquot $(50 \mu \mathrm{L})$ was injected through an autosampler on to an analytical column and the mobile phase composition changed from $0.02 \mathrm{M}$ $\mathrm{KH}_{2} \mathrm{PO}_{4}(\mathrm{pH} 3.8) / \mathrm{CH}_{3} \mathrm{CN}$ (4:1, volume (vol)/vol) to 0.02 $\mathrm{M} \mathrm{KH}_{2} \mathrm{PO}_{4}\left(\mathrm{pH} \mathrm{3.8)} / \mathrm{CH}_{3} \mathrm{CN}(5: 4, \mathrm{vol} / \mathrm{vol})\right.$ in the linear gradient mode over $40 \mathrm{~min}$. The separation was completed within 55 min for each sample, and quantification of ONO5046 in each sample were carried out on the basis of the calibration plots obtained from the peak area ratio for each standard solution. The lower detection limit of this assay was $0.15 \mu \mathrm{g} \cdot \mathrm{mL}^{-1}$.

\section{Drugs}

ONO-5046 was a gift from Ono Pharmaceutical (Osaka, Japan) and was suspended in $0.9 \%$ saline at a concentration of $100 \mathrm{mg} \cdot \mathrm{mL}^{-1}$. Pentobarbital sodium was obtained from Abbott (North Chicago, IL, USA). ACh chloride was obtained from Sigma Chemical (St Louis, MO, USA), and was dissolved in $0.9 \%$ saline.

\section{Statistical analysis}

All data are expressed as mean \pm SEM. PC200 was calculated by log-linear interpolation in individual animals, based on a previous study [24]. The effects of ONO-5046 on PC200 and on cell counts in BALF were compared by analysis of variance (ANOVA), and the significance of differences between the values was assessed using the Bonferroni correction for multiple comparisons. The time-dependent effects of ozone exposure on NE-PI concentration in BALF were assessed by multiple linear regression. The time course of the plasma concentration of ONO-5046 was assessed by ANOVA. A p-value $<0.05$ was considered to indicate statistical significance.

\section{Results}

Effects of ozone exposure on neutrophil elastase- $\alpha_{1}$ protease inhibitor concentration in bronchoalveolar lavage fluid

Figure 1 shows the time-dependent effects of ozone exposure on NE-PI concentration in BALF. In shamexposed animals, the concentration of NE-PI in BALF was below the detection limit. Immediately after ozone exposure, the NE-PI concentration increased to $124 \pm 10$ $\mu \mathrm{g} \cdot \mathrm{L}^{-1}$, and further increased to $186 \pm 17 \mu \mathrm{g} \cdot \mathrm{L}^{-1} 3 \mathrm{~h}$ after the exposure $(\mathrm{p}<0.05$, immediately after versus $3 \mathrm{~h}$ after exposure). The NE-PI concentration was $160 \pm 18 \mu \mathrm{g} \cdot \mathrm{L}^{-1} 5$ $\mathrm{h}$ after the exposure, which was still higher than that of the sham-exposed control.

\section{Effects of ONO-5046 on cell counts in bronchoalveolar lavage fluid}

Figure 2a shows the effects of ONO-5046 on neutrophil counts in BALF after ozone exposure. The number of neutrophils in BALF increased time-dependently after ozone exposure. Pretreatment with ONO-5046 showed no effect on neutrophil number either immediately or $3 \mathrm{~h}$ after ozone exposure, but significantly reduced it $5 \mathrm{~h}$ after ozone exposure $(\mathrm{p}<0.05$, ONO-5046-treated versus vehicle-treated animals).

Figure $2 \mathrm{~b}$ shows the effects of ONO-5046 on epithelial cell counts in BALF. The number of epithelial cells also increased time-dependently after ozone exposure; thus, suggesting the development of epithelial desquamation. Although pretreatment with ONO-5046 did not affect the increase in epithelial cell number immediately after ozone exposure, it significantly suppressed the further progression of epithelial desquamation 3 and $5 \mathrm{~h}$ after ozone

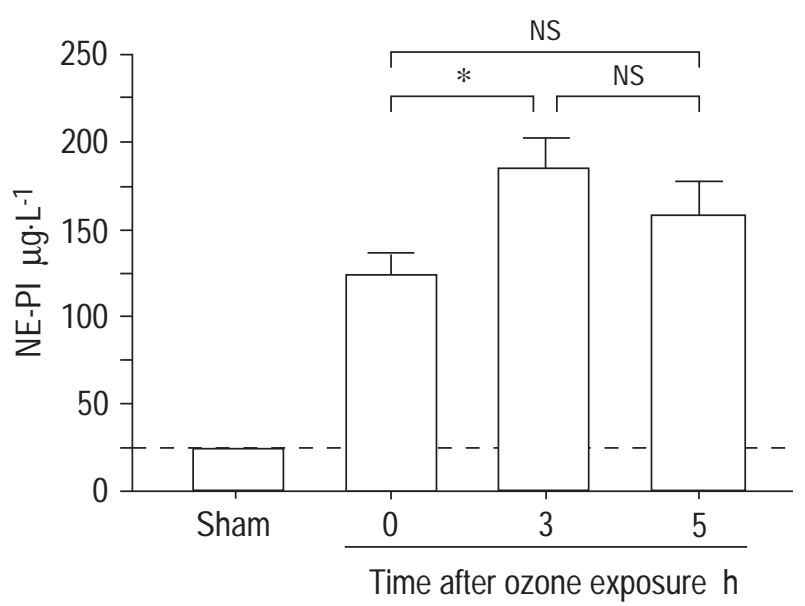

Fig. 1. - Effects of ozone exposure on neutrophil elastase- $\alpha_{1}$-protease inhibitor complex (NE-PI) concentration in bronchoalveolar lavage fluid. In sham-exposed animals, the concentration of Ne-PI in BALF was below the detection limit $\left(---;<25 \mu \mathrm{g} \cdot \mathrm{L}^{-1}\right)$. The NE-PI concentration in ozone-exposed animals was measured immediately and 3 and $5 \mathrm{~h}$ after exposure. The values represent mean $\pm \operatorname{SEM}(\mathrm{n}=5)$. *: $\mathrm{p}<0.05$. 

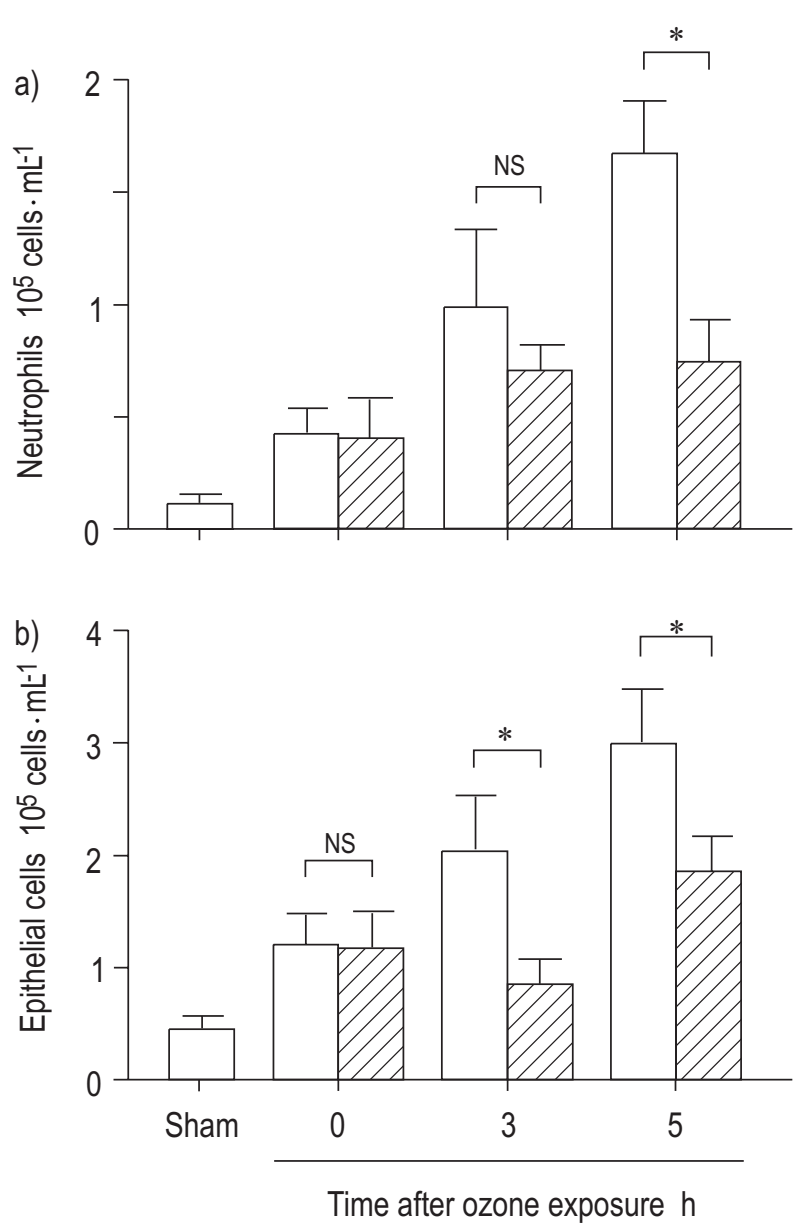

Fig. 2. - Effects of ONO-5046 on: a) neutrophil; and b) epithelial cell counts in BALF after ozone exposure. $\square$ : vehicle pretreatment; $\mathbb{Z}$ : ONO-5046 pretreatment $\left(200 \mathrm{mg} \cdot \mathrm{kg}^{-1}\right)$. The values represent mean \pm SEM $(n=5)$. Ozone exposure resulted in significantly increased cell number at all time points $(\mathrm{p}<0.05$ compared to sham-exposed animals); *: $\mathrm{p}<0.05$ compared to vehicle-treated ozone-exposed animals.

exposure (both $\mathrm{p}<0.05$, ONO-5046-treated versus vehicle-treated animals).

The number of macrophages, but not of lymphocytes nor eosinophils, was significantly suppressed immediately and $3 \mathrm{~h}$ after ozone exposure (both $\mathrm{p}<0.05$, ozone versus sham-exposed animals) (table 1). Pretreatment with ONO5046 showed no significant effect on the number of macrophages, lymphocytes and eosinophils. Pretreatment with ONO-5046 in air exposed animals had no effect on differential cell counts at any time points (data not shown).
Effects of ONO-5046 on airway responsiveness to acetylcholine

Figure 3a shows the effects of ONO-5046 on airway responsiveness to inhaled $\mathrm{ACh}$ after ozone exposure. Immediately after exposure, the $\log \mathrm{PC}_{200}$ in ozoneexposed guinea pigs $\left(1.37 \pm 1.09 \mu \mathrm{g} \cdot \mathrm{mL}^{-1}\right)$ was significantly lower than that in sham-exposed animals $(3.21 \pm$ $\left.1.08 \mu \mathrm{g} \cdot \mathrm{mL}^{-1}\right)(\mathrm{p}<0.01)$, suggesting that ozone exposure caused airway hyperresponsiveness. Subsequently, 3 and $5 \mathrm{~h}$ after exposure $\left(3 \mathrm{~h}: 1.89 \pm 1.06 \mu \mathrm{g} \cdot \mathrm{mL}^{-1} ; 5 \mathrm{~h}: 1.73 \pm\right.$ $1.14 \mu \mathrm{g} \cdot \mathrm{mL}^{-1}$ ), this airway hyperresponsiveness to ACh returned to near baseline values, but remained elevated (both $\mathrm{p}<0.05$ ). Pretreatment with ONO-5046 had no effect on $\log$ PC200 immediately after ozone exposure $\left(0.37 \pm 0.09\right.$ (vehicle-treated) versus $0.47 \pm 0.10 \mu \mathrm{g} \cdot \mathrm{mL}^{-1}$ (ONO-5046-treated); NS). However, 3 and $5 \mathrm{~h}$ after exposure, the log PC200 in animals pretreated with ONO-5046 (3 h: $2.37 \pm 1.16 \mu \mathrm{g} \cdot \mathrm{mL}^{-1}, 5 \mathrm{~h}: 2.23 \pm 1.11 \mu \mathrm{g} \cdot \mathrm{mL}^{-1}$ ) were significantly higher than those in animals pretreated with vehicle at each time point $\left(3 \mathrm{~h}: 1.89 \pm 1.06 \mu \mathrm{g} \cdot \mathrm{mL}^{-1} ; 5 \mathrm{~h}\right.$ : $\left.1.73 \pm 1.14 \mu \mathrm{g} \cdot \mathrm{mL}^{-1}\right)($ both $\mathrm{p}<0.05)$.

Figure $3 \mathrm{~b}$ shows the effects of ONO-5046 on airway responsiveness to intravenous ACh after ozone exposure. The log PC200 in ozone-exposed animals were significantly lower at all time points than those in sham-exposed animals $(0 \mathrm{~h}: 0.93 \pm 0.07,3 \mathrm{~h}: 1.20 \pm 0.09,5 \mathrm{~h}: 1.13 \pm 0.05$ versus sham-exposed: $\left.1.58 \pm 0.08 \mu \mathrm{g} \cdot \mathrm{mL}^{-1}\right)($ all $\mathrm{p}<0.05)$. In contrast to the data regarding inhaled ACh, ONO-5046 had no significant effect on log PC200 in ozone-exposed animals at any time point [0 h: $1.11 \pm 0.06$ (ONO-5046) versus $0.93 \pm 0.07 \mu \mathrm{g} \cdot \mathrm{mL}^{-1}$ (vehicle $3 \mathrm{~h} 1.24 \pm 0.10$ (ONO5046) versus $1.20 \pm 0.09 \mu \mathrm{g} \cdot \mathrm{mL}^{-1}$ (vehicle $5 \mathrm{~h}: 1.07 \pm 0.03$ (ONO-5046)) versus $1.13 \pm 0.05$ (vehicle all Ns). Pretreatment with ONO-5046 in air-exposed animals had no effect on airway responsiveness to inhaled nor intravenous $\mathrm{ACh}$ at any time points (data not shown).

\section{Plasma concentration of ONO-5046}


$1.84 \mu \mathrm{g} \cdot \mathrm{mL}^{-1}$ immediately after ozone exposure, $0.75 \pm$ $0.35 \mu \mathrm{g} \cdot \mathrm{mL}^{-1} 3 \mathrm{~h}$ after exposure and below the detection limit $\left(0.15 \mu \mathrm{g} \cdot \mathrm{mL}^{-1}\right) 5 \mathrm{~h}$ after exposure.

\section{Discussion}

The present study demonstrated that ozone exposure induced neutrophilic inflammation and epithelial injury in guinea-pig airways. In addition, ozone exposure increased

Table 1. - Effects of ONO-5046 pretreatment on cell counts in bronchoalveolar lavage fluid after ozone exposure

\begin{tabular}{|c|c|c|c|c|c|c|c|}
\hline & \multicolumn{7}{|c|}{ Cell number $10^{5}$ cells $\cdot \mathrm{mL}^{-1}$} \\
\hline & \multirow{3}{*}{ Sham } & \multicolumn{6}{|c|}{ Ozone-exposed } \\
\hline & & \multicolumn{2}{|c|}{$0 \mathrm{~h}$} & \multicolumn{2}{|c|}{$3 \mathrm{~h}$} & \multicolumn{2}{|c|}{$5 \mathrm{~h}$} \\
\hline & & Vehicle & ONO-5046 & Vehicle & ONO-5046 & Vehicle & ONO-5046 \\
\hline Macrophages & $3.32 \pm 0.43$ & $1.62 \pm 0.51^{*}$ & $2.20 \pm 0.62 *$ & $2.16 \pm 0.20 *$ & $1.94 \pm 0.58^{*}$ & $2.30 \pm 0.45$ & $2.68 \pm 0.14$ \\
\hline Lymphocytes & $0.38 \pm 0.07$ & $0.16 \pm 0.04$ & $0.16 \pm 0.05$ & $0.17 \pm 0.03$ & $0.26 \pm 0.07$ & $0.37 \pm 0.07$ & $0.39 \pm 0.12$ \\
\hline Eosinophils & $0.22 \pm 0.10$ & $0.26 \pm 0.13$ & $0.10 \pm 0.04$ & $0.36 \pm 0.15$ & $0.21 \pm 0.06$ & $0.46 \pm 0.23$ & $0.37 \pm 0.11$ \\
\hline
\end{tabular}

*: $\mathrm{p}<0.05$ compared to sham-exposed control. 

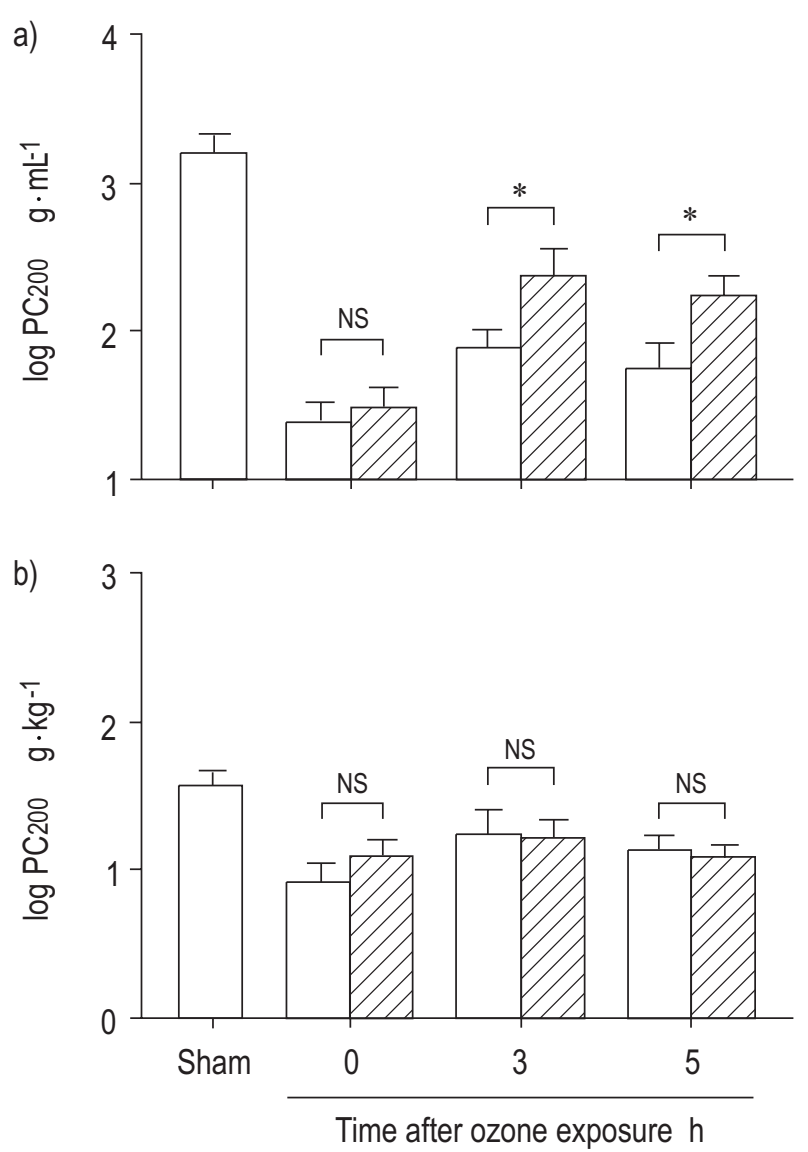

Fig. 3. - Effects of ONO-5046 on airway responsiveness after ozone exposure to acetylcholine: a) inhaled; and b) intravenous. $\square$ : vehicle pretreatment; $\mathbb{Z}$ : ONO-5046 pretreatment (200 $\left.\mathrm{mg} \cdot \mathrm{kg}^{-1}\right)$. The values represent mean $\pm \operatorname{SEM}(n=5)$. Ozone exposure resulted in significantly decreased airway responsiveness at all time points. $\mathrm{p}<0.05$ compared to sham-exposed animals); *: $p<0.05$ compared to vehicle-treated ozoneexposed animals.

the concentration of NE in BALF and airway responsiveness to both inhaled and intravenous ACh. Although an NE inhibitor, ONO-5046, had no effect on these changes immediately after the exposure, it significantly inhibited the degree of epithelial injury and airway hyperresponsiveness to inhaled ACh 3-5 h after ozone exposure. In contrast, ONO-5046 had no effect on airway hyperresponsiveness to intravenous $\mathrm{ACh}$ at any time.

In this study, ozone exposure markedly increased the concentration of NE-PI in BALF from guinea-pigs, and this finding was consistent with a previous report in which the concentration of NE increased in BALF from normal subjects exposed to $0.4 \mathrm{ppm}$ of ozone for $2 \mathrm{~h}$ [10]. As a causal mechanism of the effect of NE on airway hyperresponsiveness, this study focused on the concurrent epithelial injury which is generally observed in ozoneexposed animals. A disorder of epithelial function induces airway hyperresponsiveness by multiple mechanisms such as facilitating the diffusion of stimuli to the airway tissue [17], and decreases in the concentrations of various epithelial-derived modulators [18-22]. NE is a multipotent serine protease capable of degrading not only elastin but also type IV collagen, fibronectin, laminin and proteoglycans, all of which are components of the basement membrane and of epithelial integrity [29]. In the phy- siological state, NE activity is neutralized by various antiproteases, such as $\alpha_{1}$-proteinase inhibitor, $\alpha_{2}$-macroglobulin and secretory leukoprotease inhibitor [29], but these antiproteases are easily inactivated by oxidative stress. Indeed, ozone per se acts as a strong radical and contributes to the secondary formation of other oxygen radicals [30-32]. The protection by ONO-5046 against an increase in epithelial desquamation and airway hyperresponsiveness to inhaled ACh suggests that intrinsic NE contributes to ozone-induced disorders at least $3 \mathrm{~h}$ after the exposure.

The inhibitory effects of ONO-5046 on ozone-induced epithelial injury and airway hyperresponsiveness to inhaled ACh do not provide any direct evidence for the contribution of NE-induced epithelial injury to airway hyperresponsiveness. The possibility remains that these events might be independent from each other. In this regard, a previous study demonstrated the degree of airway hyperresponsiveness to be higher in ozone-exposed guineapigs to which ACh was administered by inhalation rather than intravenously [26]. This difference between the administration routes indicates epithelial factors to be involved in ozone-induced airway hyperresponsiveness $[23,24]$. If epithelial injury plays an important role in airway hyperresponsiveness and the effect of $\mathrm{NE}$ is localized on the epithelium, the effect of ONO-5046 on airway responsiveness should differ in animals receiving ACh administered via either the inhaled or the intravenous route. Therefore, the effect of ONO-5046 on ozoneinduced airway hyperresponsiveness to intravenous ACh was examined. The lack of any inhibitory effect of ONO5046 on airway hyperresponsiveness to intravenous ACh strongly suggests NE-mediated epithelial injury to play a pivotal role in airway hyperresponsiveness in this experimental model.

Although ONO-5046 significantly inhibited ozone-induced airway hyperresponsiveness to inhaled ACh, it did not completely inhibit it. This compound seems to account for one-third of the effect observed at 3 and $5 \mathrm{~h}$ after ozone exposure. One possibility is that the dose of ONO-5046 administered was not sufficient to abolish NE activity. However, this possibility is unlikely for the following reason. According to the manufacturer's written specification, ONO-5046 shows excellent distribution from plasma into lung tissue (personal communication). In addition, ONO5046 inhibits guinea-pig NE activity in a concentrationdependent manner (IC50 23.2 $\pm 1.2 \mathrm{nM}$ ) [28]. An IC50 of $23.2 \mathrm{nM}$ is equivalent to $1.23 \times 10^{-4} \mu \mathrm{g} \cdot \mathrm{mL}^{-1}$, which is far lower than the plasma concentrations of ONO-5046 measured in animals immediately and $3 \mathrm{~h}$ after ozone exposure $\left(3.89 \pm 1.84\right.$ and $0.75 \pm 0.35 \mu \mathrm{g} \cdot \mathrm{mL}^{-1}$, respectively). Although the concentration $5 \mathrm{~h}$ after exposure was below the detection limit $\left(<0.15 \mu \mathrm{g} \cdot \mathrm{mL}^{-1}\right)$, it remains possible that the concentration was still sufficient to block NE activity. Therefore, it is strongly suggested that intrinsic $\mathrm{NE}$ activity was effectively inhibited by ONO-5046 in this study at all time points. Another explanation for the incomplete inhibition of airway hyperresponsiveness by ONO-5046 is that there may be other mechanisms accounting for the hyperresponsiveness to inhaled ACh. The observation that airway hyperresponsiveness to intravenous ACh was not affected by ONO-5046 supports, at least in part, this latter explanation. It may suggest the 
existence of a common pathway in ozone-induced airway hyperresponsiveness to inhaled and intravenous ACh.

ONO-5046 had no effect on airway hyperresponsiveness or epithelial injury immediately after ozone exposure. Based on previous findings, it is speculated that ozoneinduced airway hyperresponsiveness involves multiple mechanisms, including the release of eicosanoids and airway neural activation in addition to epithelial injury $[9,12$, 24]. Mechanisms other than epithelial injury by NE may also play a role immediately after ozone exposure. For example, it was previously shown that both the ozoneinduced airway hyperresponsiveness and neutrophilia in BALF immediately after ozone exposure are inhibited via a depletion of tachykinins by systemic capsaicin pretreatment [12]. In the early phase of ozone exposure, tachykinins, but not NE, may play a crucial role in airway hyperresponsiveness and neutrophilic inflammation. As to epithelial damage in the early phase, ozone and related free radicals may directly injure the epithelial layer. This speculation is supported by a previous report showing that oxidants directly reduce epithelial barrier functions by damaging the tight junctions of cultured human tracheal epithelial cells [33]. The following release of NE from recruited neutrophils may exacerbate the epithelial injury, which was observed in the late phase of the present study. The knowledge that the enzymatic activity of NE is potentiated in the presence of oxygen radicals further supports this possibility [34].

The contribution of neutrophils to ozone-induced airway hyperresponsiveness in guinea-pigs has been questioned by some investigators $[13,14]$. A previous study showed ozone exposure to cause airway hyperresponsiveness even in animals depleted of neutrophils by cyclophosphamide [14]. In that study, airway hyperresponsiveness was evaluated by means of intravenous ACh administration. In the present study, ozone-induced airway hyperresponsiveness to intravenous ACh was not affected by ONO5046 pretreatment, but airway hyperresponsiveness to inhaled ACh was significantly suppressed by ONO-5046. These results may, thus, not conflict with the findings of previous reports, if the neutrophils and NE contribute only to airway hyperresponsiveness to inhaled bronchoconstrictors.

The finding that ONO-5046 inhibited the recruitment of neutrophils in BALF $5 \mathrm{~h}$ after ozone exposure may provide in vivo evidence for the significance of intrinsic $\mathrm{NE}$ as a mediator which causes a subsequent accumulation of neutrophils. Aerosolized NE has been reported to induce airway hyperresponsiveness and the recruitment of polymorphonuclear cells to the airway epithelium in intrapulmonary bronchi [16]. A previous in vitro study reported that treatment with $\mathrm{NE}$, using concentrations at which there was no fatal toxic effect on the cells, increased production of interleukin-8 (IL-8), a potent chemokinc for neutrophils, in cultured airway epithelial cells [35]. The interactions between activated neutrophils and epithelial cells may constitute the NE- and IL-8-mediatid vicious cycle, thus contributing to the persistence of neutrophilic airway inflammation.

Recently, HiLTERmann et al. [36] reported the effect of recombinant antileukoprotease (rALP) on ozone-induced airway hyperresponsiveness in patients with asthma. They observed that airway responsiveness to inhaled methacholine was increased $16 \mathrm{~h}$ after ozone exposure, and was accompanied by neutrophilic airway inflammation. However, rALP treatment did not protect against ozoneinduced airway hyperresponsiveness. the role of neutrophil-derived proteases in asthmatics remains uncertain; thus, further studies are needed.

In summary, ozone exposure induced neutrophilic inflammation and epithelial injury in guinea-pig airways. Ozone exposure increased the concentration of neutrophil elastase in bronchoalveolar lavage fluid and airway responsiveness to both inhaled and intravenous acetylcholine. Although the neutrophil elastase inhibitor, ONO-5046, significantly inhibited epithelial injury and airway hyperresponsiveness to inhaled acetylcholine, it had no effect on airway hyperresponsiveness to intravenous acetylcholine.

These results, therefore, suggest that neutrophil elastase contributes to ozone-induced airway hyperresponsiveness, presumably by inducing epithelial injury.

Acknowledgements. The authors are grateful to Ono Pharmaceutical Co. (Osaka, Japan) for the donation of ONO-5046 and for the measurement of plasma concentrations of ONO-5046.

\section{References}

1. Bousquet J, Chanez P, Lacoste JY, et al. Eosinophilic inflammation in asthma. N Engl J Med 1990; 323: 10331039.

2. Sur S, Crotty TB, Kephart GM, et al. Sudden onset fatal asthma. A distinct entity with few eosinophils and relatively more neutrophils in the airway submucosa. $\mathrm{Am} \mathrm{Rev}$ Respir Dis 1993; 148: 713-719.

3. Lamblin C, Gosset P, Tillie-Leblond I, et al. Bronchial neutrophilia in patients with noninfectious status asthmaticus. Am J Respir Crit Care Med 1998; 157: 394-402.

4. Boschetto P, Mapp CE, Picotti G, Fabbri LM. Neutrophils and asthma. Eur Respir J 1989; 6(suppl.): 456-459.

5. Golden JA, Nadel JA, Boushey HA. Bronchial hyperreactivity in healthy subjects after exposure to ozone. $\mathrm{Am}$ Rev Respir Dis 1978; 118: 287-294.

6. Holtzman MJ, Fabbri LM, O'Byrne PM, et al. Importance of airway inflammation for hyperresponsiveness induced by ozone. Am Rev Respir Dis 1983; 127: 686-690.

7. Fabbri LM, Aizawa H, Alpert SE, Walters EH, et al. Airway hyperresponsiveness and changes in cell counts in bronchoalveolar lavage after ozone exposure in dogs. $\mathrm{Am}$ Rev Respir Dis 1984; 129: 288-291.

8. O'Byrne PM, Walters EH, Gold BD, et al. Neutrophil depletion inhibits airway hyperresponsiveness induccd by ozone-exposure. Am Rev Respir Dis 1984; 130: 214-219.

9. Aizawa H, Chung KF, Leikauf GD, et al. Significance of thromboxane generation in ozone-induced airway hyperresponsiveness in dogs. J Appl Physiol 1985; 9: 1918 1923.

10. Koren HS, DevIin RB, Graham DE, et al. Ozone-induced inflammation in the lower airways of human subjects. $\mathrm{Am}$ Rev Respir Dis 1989; 139: 407-415.

11. Aris RM, Christian D, Hearne PQ, Kerr K, Finkbeiner WE, Balmes JR. Ozone-induced airway inflammation in human subjects as determined by airway lavage and biopsy. Am Rev Respir Dis 1993; 148: 1363-1372.

12. Koto $\mathrm{H}$, Aizawa $\mathrm{H}$, Takata $\mathrm{S}$, Inoue $\mathrm{H}$, Hara N. An important role of tachykinins in ozone-induced airway 
hyperresponsiveness. Am J Respir Crit Care Med 1995; 151: 1763-1769.

13. Murlas CG, Roum JH. Sequence of pathologic changes in the airway mucosa of guinea-pigs during ozone-induced bronchial hyperreaciivity. Am Rev Respir Dis 1985; 131: 314-320.

14. Murlas CG, Roum JH. Bronchial hyperreactivity occurs in steroid-treated guinea pigs depleted of leukocytes by cyclophosphamide. J Appl Physiol 1985; 58: 16301637.

15. Vignola AM, Bonanno A, Mirabella A, et al. Increased levels of elastase and alphal-antitrypsin in sputum of asthmatic patients. Am J Respir Crit Care Med 1998; 157: 505-511.

16. Suzuki T, Wang W, Lin J-T, Shirato K, Mitsuhashi H, Inoue $\mathrm{H}$. Aerosolized human neutrophil elastase induces airway constriction and hyperresponsiveness with protection by intravenous pretreatment with half-length secretory leukoprotease inhibitor. Am J Respir Crit Care Med 1996; 153: 1405-1411.

17. Boucher RC, Pare PD, Hogg JC. Relationship between airway hyperreactivity and hyperpermeability in Ascarissensitive monkeys. J Allergy Clin Immunol 1979; 64: 197-201.

18. Flavahan NA, Aarhus LL, Rimele TJ, Vanhoutte PM. Respiratory epithelium inhibits bronchial smooth muscle tone. J Appl Physiol 1985; 58: 834-838.

19. Aizawa H, Miyazaki N, Shigematsu N, Tomooka M. A possible role of airway epithelium in modulating hyperresponsiveness. Br J Pharmacol 1988; 93: 139-145.

20. Barnett K, Jacoby DB, Nadel JA, Lazarus SC. The effects of epithelial cell supernatant on contractions of isolated canine tracheal smooth muscle. Am Rev Respir Dis 1988; 138: 780-783

21. Figini M, Ricciardolo FLM, Javdan P, et al. Evidence that epithelium-derived relaxing factor released by bradykinin in the guinea pig trachea is nitric oxide. Am J Respir Crit Care Med 1996; 153: 918-923.

22. Matsumoto K, Aizawa H, Inoue R, et al. Effects of epithelial cell supernatant on membrane potential and contraction of dog airway smooth muscles. Am J Respir Cell Mol Biol 1994; 10: 322-330.

23. Murlas CG, Murphy TP, Chodimella V. $\mathrm{O}_{3}$-induced mucosa-linked airway muscle hyperresponsiveness in the guinea pigs. J Appl Physiol 1990; 69: 7-13.
24. Takata S, Aizawa H, Inoue H, Koto H, Hara N. Ozone exposure suppresses epithelium-dependent relaxation in feline airway. Lung 1995; 173: 47-56.

25. Kawabata K, Suzuki M, Sugitani M, Imaki K, Toda M, Myamoto T. ONO-5046, a novel inhibitor of human neutrophil elastase. Biochem Biophys Res Commun 1991; 177: 814-820.

26. Roum JR, Murlas CG. Ozone-induced changes in muscarinic bronchial hypereactivity by different testing methods. J Appl Physiol 1984; 57: 1783-1789.

27. James AL, Dirks P, Ohtaka H, Schellenberg RR, Hogg JC. Airway responsiveness to intravenous and inhaled acethylcholine in the guinea pig after cigarette smoke exposure. Am Rev Respir Dis 1987; 136: 1158-1162.

28. Sakamaki F, Ishizaka A, Urano T, et al. Effect of a specific neutrophil elastase inhibitor, ONO-5046, on endotoxin-induced acute lung injury. Am J Respir Crit Care Med 1996; 153: 391-397.

29. Hubbard RC. The Lung: Scientific foudations (ed by Crystal, R.G. and West, J.B.). Raven Press, New York, 1991, pp. 1763-1787.

30. Pryor WA, Church DF. Aldehydes, hydrogen peroxide, and organic radicals as mediators of ozone toxicity. Free Radical Biol Med 1991; 11: 41-46.

31. Stevens WHM, Conlon PD, O'Byme PM. Ozone-induced oxygen radical release from bronchoalveolar lavage cells and airway hyper-responsiveness in dogs. J Physiol 1995; 486: 257-265.

32. Chen LC, Qu Q. Formation of intracellular free radicals in guinea pig airway epithelium in vitro exposure to ozone. Toxcol Appl Pharmacol 1997; 143: 96-101.

33. Yamaya M, Sekizawa K, Matsuda T, Morikawa M, Sawai T, Sasaki H. Oxidants affect permeability and repair of the cultured human tracheal epithelium. Am J Physiol 1995; 268: L284-293.

34. Travis J, Salvesen GS. Human plasma proteinase inhibitors. Annu Rev Biochem 1983; 52: 655-709.

35. Shibala Y, Nakamura H, Kato S, Tomoike H. Cellular detachement and deformation induce IL-8 gene expression in human bronchial epithelial cells. J Immunol 1996; 156: 772-777.

36. Hiltermann TJ, Peters EA, Alberts B, et al. Ozone-induced airway hyperresponsiveness in patients with asthma: role of neutrophil-derived serine proteinases. Free Radic Bilo Med 1998; 24: 952-958. 